\title{
Characterization and Determination of Antibiotic Sensitivity Profile of Pseudomonasaeruginosa Isolated from Infected Wound
}

\author{
Muhammad Ali $^{1 *}$, Sani U. Diso ${ }^{2}$, Idris S. Ibrahim ${ }^{2}$, Sumayya A. Wayya ${ }^{3}$ \\ ${ }^{l}$ Department of Microbiology, Federal University Gusau \\ ${ }^{2}$ Department of Pharmaceutical Technology, School of Technology, Kano State Polytechnics \\ ${ }^{3}$ School of Hygiene, Kano
}

*Corresponding Author: Muhammad Ali, Department of Microbiology, Federal University Gusau

Email: alimuhd4real@gmail.com

\begin{abstract}
Microbial resistance to antibiotics is one of the most serious health threats threatening human well-being today. The study was aimed to characterized and determine the antimicrobial sensitivity profile of $P$. aeruginosa isolated from infected wound. Swap sticks containing a total of 52 samples from different types of wound (trauma, sepsis, surgical and bite wound) were collected from Microbiology laboratory of Abdullah Wase Special Hospital Kano State for isolation and characterization of Pseudomonasaeruginosa. The samples from swap containing pus from patients were inoculated onto the surface of nutrient agar plate and incubated for 24 hours at 370C. Each colony was isolated in a pure form by sub culturing for further studies and identification. Further microbial identification (Gram staining and biochemical characterization including catalase, coagulase and oxidase tests) were conducted. The isolates were subjected to antibiotic susceptibility testing using agar disc diffusion method. From the 52 total samples, 35 were found to be positive for P.aeruginosaaccounted for 67.3\%. Higher prevalence of the isolated was recorded surgical wound $11(31.43 \%)$, followed by trauma wound $10(28.57 \%)$, sepsis $8(22.86 \%)$ and least prevalence was found in bite wound $6(17.14 \%)$. The result showed that the P. aeruginosa isolates are resistant to Norfloxacin, Amoxicillin, erythromycin, Ampicillin and Chloramphenicol while sensitive to ciprofloxacin, gentamicin, and levofloxacin. Isolates were intermediate sensitive to streptomycin and rifampicin. There is significant difference on the sensitivity of the isolates to the antibiotics tested at $p<0.05$. It is concluded that $P$. aeruginosa is one organism responsible for deterioration of wound.
\end{abstract}

Keywords: Antibiotics, sensitivity profile, resistance, Pseudomonas aeruginosa

\section{INTRODUCTION}

Microbial resistance to antibiotics is one of the most serious health threats threatening human well-being today. Antibiotic resistance is a type of drug resistance where a microorganism is able to survive exposure to an antibiotic [1]. Infections from resistant bacteria are now too common and some pathogens have even become resistant to multiple types or classes of antibiotics. The widespread use of antibiotics both inside and outside of medicine is playing a significant role in the emergence of resistant bacteria [2]. One such microbial resistance of much interest nowadays to the scientific world in general and medical perspective in particular is the resistance of Pseudomonas aeruginosato different class of antibiotics.

$P$. aeruginosa is obligate aerobe, motile, rodshaped, measure about $0.6 \times 2 \mu \mathrm{m}$. It is gramnegative and occurs as single bacteria, in pairs, and occasionally in short chains, sometimes producing a sweet or grape-like or corn taco-like odor [3]. Its production of blue pigments called pyocyanin differentiates it from most other Gram-negative bacteria. The Pyocyanin produced and fluorescin combined produce a bright green color that diffuses throughout the medium [4]. $P$ aeruginosa grows well at 37-42 ${ }^{\circ} \mathrm{C}$; its growth at $42{ }^{\circ} \mathrm{C}$ helps differentiate it from other Pseudomonas species. It does not ferment carbohydrates, but many strains oxidize glucose [3]. P. aeruginosa normally inhabit soil, water, and vegetation and can be isolated from the skin, throat, and stool of healthy persons. They often colonize hospital food, sinks, taps, mops, and respiratory equipment [5]. Pseudomonas aeruginosa causes infections in healthy individuals and those who are hospitalized or have a compromised immune system as a result of other diseases. A variety of 
human infections such as wound are commonly associated with this bacterium.

Wound infection can best describe as the deposition and multiplication of microbes especially bacteria in tissue with an associated host reaction [6]. Infection in a wound delays healing and may cause wound break down, herniation of the wound and complete wound dehiscence [7]. Therefore the knowledge of the causative agents of wound infection will be helpful in the control of wound infection and selection of empiric antimicrobial therapy as an infection control measure [8].

Aerobic pathogens such as Staphylococcus aureus, Pseudomonasaeruginosa, and beta haemolytic Streptococci have been most frequently reported as the cause of delay wound healing [9]. A study on aerobic bacterial profile and antimicrobial susceptibility pattern of wound isolates in a South Indian tertiary care hospital revealed S. aureus $(24.29 \%)$ was the most common isolate; this is followed by $P$. aeruginosa (21.49\%), E. coli (14.02\%), Klebsiella pneumoniae (12.15\%), Streptococcus pyogenes $(11.23 \%)$, S. epidermidis $(09.35 \%)$ and Proteus sp $(07.47 \%)$ [10]. In another study conducted by Verma and Chitra[11]on isolation of different types of bacteria from infected wound also revealed thatStaphylococcus aureus as the most predominant microorganism accounted for $40 \%$ of the total isolates obtained, followed by Klebsiella sp (33\%), P. aeruginosa (18\%), E. coli (16\%) and Proteus sp (07\%) [11]. the emergence of bacterial antimicrobial resistance has made the choice of empirical therapy more difficult and expensive [12]. As result, regular screening of causative organism and determination of susceptibility pattern of such organisms to commonly used antibiotics is neededfor empirical treatment of infections. The study was aimed to characterized and determine the antimicrobial sensitivity profile of $P$. aeruginosa isolated from infected wound.

\section{Materials AND Methods}

\subsection{Study Area}

The study area is Kano metropolis, samples from infected wound patients were collected from Muhammad Abdullahi Wase Hospital in the state capital. Kano State is a state located in North-Western Nigeria and one of the largest State of the Nigerian Federation, it is bordered by Katsina State to the North-West, Jigawa State to the North-East, Bauchi State to the South-East and Kaduna State to the South-West.
Kano is located on $12^{\circ} \mathrm{N}$ and $8^{\circ} 30^{\prime} \mathrm{E}$. It has a total area of $20,131 \mathrm{~km}^{2}$. The urban area covers $137 \mathrm{~km}^{2}$ and comprises of six LGAs - Kano municipal, Fagge, Dala, Gwale, Tarauni and Nassarawa with population of $2,163,25$ as at 2006 [13].

\subsection{Ethical Clearance}

Ethical approval (Issue number: HMB/ GEN/488/Vol. I) was obtained from Health Service Management board (HSMB) Kano State based on the consent of Muhammad Abdullahi Wase Specialists Hospital (MAWSH) Ethical Committees.

\subsection{Sample Collection}

The swap sticks containing a total of 52 samples from different types of wound (trauma, sepsis, surgical and bite wound) were collected from Microbiology laboratory of Abdullahi Wase Special Hospital Kano State for isolation and characterization of Pseudomonasaeruginosa.

\subsection{Isolation and Identification of Pseudomonasaeruginosa}

The samples from swap containing pus from patients were inoculated onto the surface of nutrient agar plate and incubated for 24 hours at $37^{\circ} \mathrm{C}$. Each colony was isolated in a pure form by sub culturing for further studies and identification. Distinctive morphological properties of each pure culture such as colony form, elevation of colony and colony margin were observed. Further microbial identification (Gram staining and biochemical characterization including catalase, coagulase and oxidase tests) was based on the methods of Cheesbrough [14] and Holt et al. [15].

\subsection{Gram Staining}

A drop of normal saline was placed on a well labeled clean grease-free glass slide using a sterile inoculating loop; a colony of an overnight culture of the bacterial isolate was emulsified with the normal saline to make a thin smear. The smear was air dried and then heat fixed. The slide was flooded with crystal violet (primary stain) for 30 seconds after which the stain was rinsed from the slide with water. The smear was flooded with Lugol's iodine (mordant) to fix the primary stain. The iodine was rinsed with water after 60 seconds. The slide was then flooded with a decolorizer (acetone) and rinsed off almost immediately. The counter stain; safranin was added and left for 30 seconds before being rinsed off. The stained smear was air dried, and then observed 
under the microscope using X100 oil immersion objective lens of the microscope.

\subsection{Catalase Test}

A microscope slide was placed inside a Petri dish. The Petri dish cover was kept available. Using sterile inoculating loop, a small amount of organism was collected from a well-isolated 24-hour colony and placed it onto the microscope slide. Using a dropper, 1 drop of $3 \%$ $\mathrm{H}_{2} \mathrm{O}_{2}$ was dropped onto the organism on the microscope slide.

\subsection{Coagulase Test}

$0.5 \mathrm{ml}$ of blood plasma was added into a test tube and $0.1 \mathrm{ml}$ of the test organism was added and observed after 30 minutes at room temperature

\subsection{Oxidase Test}

A small piece of filter paper was soaked in $1 \%$ oxidase reagent and let dried. Using a sterile loop a well-isolated colony from a fresh 24hours culture of bacterial plate was removed and rubbed onto treated filter paper and observed for color changes.

\subsection{Antibiotic Sensitivity Test}

The isolates were subjected to antibiotic susceptibility testing using agar disc diffusion method as described by Bauer et al. [16]. Mueller Hinton agar (MHA) plates were inoculated with overnight culture of each isolate by streak plating. The standard antibiotic sensitivity discs were then aseptically placed at equidistance on the plates and allowed to stand for 1 hour. The plates were then incubated at $37^{\circ} \mathrm{C}$ for 24 hours. Sensitivity pattern of the isolates to

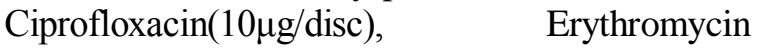
(30 $\mu \mathrm{g} / \mathrm{disc}), \quad$ Streptomycin $\quad(30 \mu \mathrm{g} / \mathrm{disc})$, Amoxicillin $(20 \mu \mathrm{g} / \mathrm{disc})$, Gentamicin $(10 \mu \mathrm{g} / \mathrm{disc})$, Ampicillin $(30 \mu \mathrm{g} / \mathrm{disc})$, Levofloxacin $(20 \mu \mathrm{g} / \mathrm{disc})$, Norfloxacin $(10 \mu \mathrm{g} / \mathrm{disc})$, Rifampicin $(20 \mu \mathrm{g} / \mathrm{disc})$ and Chloramphenicol $(20 \mu \mathrm{g} / \mathrm{disc})$, produced by Optus pharmaceutical limited, were determined. Isolates were divided into three groups based on the zone of inhibition produced by the antibiotic disc; susceptible, intermediately susceptible and resistant according to the Clinical and Laboratory Standards Institute (CLSI) guideline; Performance Standards for Antimicrobial Susceptibility Testing [17].

\subsection{Statistical Analysis}

Data analysis was done using Minitab express statistical software version 7 , where one way ANOVA was used to assess the mean diameter of zone of inhibition of the antibiotics used against the isolates. The prevalence of the isolates was analyzed using Chi square. The level of significance was set at $p$-value $<0.05$.

\section{ReSUltS}

\subsection{Identification of Pseudomonasaeruginosa}

The cultural and biochemical characteristics of P.aeruginosa are presented in Table 1. The result shows that P.aeruginosa was found to be Gram negative rod showing green pigment colony appearance on Nutrient agar plate and colorless colony in MacConkey agar plate. The isolates are positive to catalase and oxidase test but coagulase negative.

Table1: Cultural and Biochemical characteristics of Pseudomonasaeruginosa

\begin{tabular}{|l|l|l|}
\hline S/N & \multicolumn{1}{|c|}{ Test } & \multicolumn{1}{c|}{ P.aeruginosa } \\
\hline 1 & Gram staining & Gram negative \\
\hline 2 & Shape & Rod \\
\hline 3 & Cultural appearance & Produce colony with green pigments \\
\hline 4 & MacConkey growth & Produce colorless colony \\
\hline 5 & Catalase test & + \\
\hline 6 & Coagulase & - \\
\hline 7 & Oxidase & + \\
\hline
\end{tabular}

\subsection{Prevalence of Pseudomonasaeruginosa}

The prevalence of P.aeruginosa isolated from different types of wound is presents in Table 2 below. A total of 52 samples, 13 each from trauma, sepsis, surgical and bite wound were examined. From the 52 total samples, 35 were found to be positive for P.aeruginosaaccounted

Table2: Prevalence of Pseudomonasaeruginosa from different types of wound
\begin{tabular}{|l|l|l|l|c|}
\hline Type of wound & No. of samples (n) & Positive samples (n) & Prevalence (\%) & $\mathbf{X}^{\mathbf{2}}$ \\
\hline Trauma & 13 & 10 & 28.57 & $1.0455^{*}$ \\
\hline Sepsis & 13 & 8 & 22.86 & \\
\hline Surgical & 11 & 31.43 & \\
\hline
\end{tabular}

for $67.3 \%$. Higher prevalence of the isolated was recorded surgical wound 11 (31.43\%), followed by trauma wound 10 (28.57\%), sepsis $8(22.86 \%)$ and least prevalence was found in bite wound $6(17.14 \%)$. The result was not statistically significant at $p<0.05$. 
Characterization and Determination of Antibiotic Sensitivity Profile of Pseudomonasaeruginosa Isolated from Infected Wound

\begin{tabular}{|l|l|l|l|l|}
\hline Bite & 13 & 6 & 17.14 & \\
\hline Total & $\mathbf{5 2}$ & $\mathbf{3 5}$ & $\mathbf{1 0 0}$ & \\
\hline
\end{tabular}

Key: * The p-value is .79025 and the result is not significant at $p<0.05$

\subsection{Antibiotic Sensitivity Testing}

The mean zone of inhibition of antibiotic sensitivity disc against $34 P$. aeruginosa isolates is presented in Table 3. The result showed that the $P$. aeruginosa isolates are resistant to Table3: Antibiotic Sensitivity Testing of the isolates against some antibiotics

\begin{tabular}{|l|l|l|l|l|}
\hline S/N & \multicolumn{1}{|c|}{ Antibiotics } & \multicolumn{1}{c|}{ Conc. $(\boldsymbol{\mu g} /$ disc) } & \multicolumn{1}{|c|}{ Zone of inhibition $(\mathbf{m m})$} & \multicolumn{1}{|c|}{ Inference } \\
\hline 1 & Ciprofloxacin & 10 & $21.35 \pm 2.04^{\mathrm{c}}$ & Sensitive \\
\hline 2 & Norfloxacin & 10 & $10.00 \pm 0.00^{\mathrm{a}}$ & Resistance \\
\hline 3 & Gentamicin & 10 & $23.60 \pm 1.80^{\mathrm{c}}$ & Sensitive \\
\hline 4 & Amoxicillin & 20 & $10.00 \pm 0.00^{\mathrm{a}}$ & Resistance \\
\hline 5 & Streptomycin & 30 & $16.50 \pm 1.10^{\mathrm{b}}$ & Intermediate \\
\hline 6 & Erythromycin & 30 & $10.00 \pm 0.00^{\mathrm{a}}$ & Resistance \\
\hline 7 & Rifampicin & 20 & $17.00 \pm 1.50^{\mathrm{b}}$ & Intermediate \\
\hline 8 & Ampicillin & 30 & $10.00 \pm 0.00^{\mathrm{a}}$ & Resistance \\
\hline 9 & Levofloxacin & 20 & $20.10 \pm 1.67^{\mathrm{c}}$ & Sensitive \\
\hline 10 & Chloramphenicol & 20 & $10.00 \pm 0.00^{\mathrm{a}}$ & Resistance \\
\hline
\end{tabular}

Key: Values having different superscript on the same column are considered significantly different apt $<0.05$

\section{DISCUSSION}

In recent years, the progressive increase in antibiotic resistance among $P$. aeruginosa has been identified as the main reason for antibiotic inadequacy, with a negative impact on patient survival [18]. Cultural characteristics of $P$. aeruginosa on nutrient agar showed presence of green pigments. The green pigments is due to the production of Pyocyanin and fluorescin which diffuse through the medium [4]. The isolates are positive for both catalase and oxidase test. Positive for catalase test is due to presence of enzyme catalase which broke down hydrogen peroxide into water and oxygen gas while production of cytochrome c oxidase by $P$. aeruginosa accounted for positive reaction to oxidase test. However, P. aeruginosa cannot ferment lactose, thereby producing colorless colony in MacConkey agar. The prevalence of P.aeruginosaisolated from different types of wound showed out of 52 total samples, 35 were found to be positive for P.aeruginosaaccounted for $67.3 \%$. Higher prevalence of the isolated was recorded surgical wound 11 (31.43\%), followed by trauma wound $10(28.57 \%)$, sepsis $8(22.86 \%)$ and least prevalence was found in bite wound $6(17.14 \%)$. High prevalence from surgical wound could be attributed to contamination of medical devices. According to CDC [1], $P$. aeruginosa is the most common cause of infections of burn injuries and of the outer era (otitis externa), and is the most frequent colonizer of medical devices such as catheter. It can be spread by equipment that get
Norfloxacin, Amoxicillin, erythromycin, Ampicillin and Chloramphenicol while sensitive to ciprofloxacin, gentamicin, and levofloxacin. Isolates were intermediate sensitive to streptomycin and rifampicin. contaminated and is not properly cleaned or on the hands of health worker Finding from the present study showed that $P$. aeruginosa isolates were resistant to Norfloxacin, Amoxicillin, erythromycin, Ampicillin and Chloramphenicol while sensitive to ciprofloxacin, gentamicin, and levofloxacin. Isolates were intermediate sensitive to streptomycin and rifampicin.

Recently, Scientists have been examining the possible genetic basis for $P$. aeruginosaresistance to antibiotics. One locus identified as being an important genetic determinant of the resistance in $P$. aeruginosais $n d v B$, which encodes perisplasmicglucans that may interact with antibiotics and cause them to become sequestered into the periplasm[19]. Bacteria exhibit multiple resistance mechanisms to antibiotics including decreased permeability, expression of efflux systems, production of antibiotic inactivating enzymes and target modifications. $P$. aeruginosa exhibits most of these known resistance mechanisms through both intrinsic chromosomally encoded or genetically imported resistance determinants affecting the major classes of antibiotics such as $\beta$-lactams and polymyxins [20].

\section{CONClusion}

Finding from the present study revealed that $P$. aeruginosa is one organism responsible for deterioration of wound. From the 52 total samples, 35 were found to be positive for P.aeruginosaaccounted for $67.3 \%$. Higher prevalence of the isolated was recorded surgical wound, followed by trauma wound, sepsis and 
least prevalence was found in bite wound. $P$. aeruginosa isolates are found to be resistant to Norfloxacin, Amoxicillin, erythromycin, Ampicillin and Chloramphenicol while sensitive to ciprofloxacin, gentamicin, and levofloxacin. It is recommended that there is need to improve early diagnosis and empirical treatment of severe $P$. aeruginosa infections.

\section{ACKNOWLEDGEMENT}

The authors hereby wish to acknowledge to the staff of Microbiology Department of Muhammad Abdullahi Wase Specialists Hospital (MAWSH) Kano State for sample provision. Thanks to the technical staff of Microbiology Department Kano University of Science and Technology Wudil, for the use of laboratory facilities.

\section{REFERENCES}

[1] Center for Diseases Control (CDC). (2014). Pseudomonas aeruginosain Health setting: Health care-associated infection (HAI): Diseases and organisms

[2] Goossens H, Ferech M, Vanderstichele R, and Elseviers M, (2005). Outpatient antibiotics use in Europe and association with resistance, a grass national data base study. Lancet 385 (94 59): 579 - 87.

[3] Brook me (1996) Aerobic and anaerobic microbiology of necrotizing fasciitis in children. PediatrDermatol 13(4): 281-284.6.

[4] Ryan, K.J. and Ray, C.G. (2004). Sherris Medical Microbiology: An Introduction to Infectious Diseases. 4th edition.McGraw Hill Publishers.

[5] Baron, S. (1996). Medical Microbiology, 4th edition. The University of Texas Medical Branch at Galveston, Texas.

[6] Ayton M. (1985). Wound care. Wounds that won't heal.Nurs. Times. 81:16-19.

[7] Rubin RH Surgical wound infection: epidemiology, pathogenesis, diagnosis and management. BMC Infect Dis 2006; 6: 171-172.

[8] Gambo SB, Ali M, Diso SU, Abubakar NS (2018). Antibacterial Activity of Honey Against Staphylococcus Aureus and Pseudomonas Aeruginosa Isolated from Infected Wound. Arch Phar and Pharmacol Res. 1(2): APPR.MS.ID.000506.

[9] Gardner, S.E., Frontz R.A, Docbbeling B.N. (2001). The validity of the clinical signs and symptoms used to identify localized chronic wound infection. Wound Repair Regen. 9:78-86.

[10] Rao R, Sumathi, S, Anuradha K (2013) Bacteriology of postoperative wound infections. Int $\mathrm{J}$ pharm biomed res 4(2): 72-76.7.

[11] Verma VC, Chitra (2012) Antibiotic sensitivity treatment for gram negative bacteria isolated from pus sample. International Journal of Pharmacy and Biological Sciences 2(3): 359-3 63.

[12] Andhoga J, Macharia AG, Maikuma IR. et al. (2002). Aerobic pathogenic bacteria in postoperative wounds at Moi Teaching and Referral Hospital.East African med journal. 79(12), 640644.

[13] National Population Commission (NPC) (2006). National Population Census result Abuja, Nigeria. 2006

[14] Cheesbrough M (2000) District laboratory practice in tropical countries. Cambridge United Press, UK, 27: 105

[15] Holt JG, Krieg NR, Sneath PA, Stanley JT, Williams ST (1994) Bergey's manual of systematic bacteriology, (9th edn). Williams \& Wilkins Co.

[16] Bauer AW, Kirby WM, Sherris JC and Turck M (1966). Antibiotic susceptibility testing by a standardized single disk method.Am J ClinPathol.45: 493-496.

[17] CLSI, (2010) "Performance standards for antimicrobial susceptibility testing," Twentieth informational supplement, Clinical and Laboratory Standards Institute Doc. M100eS20, 2010.

[18] Garnacho-Montero J, Sa-Borges M, SoleViolan J, Barcenilla F, Escoresca-Ortega A, Ochoa M, Cayuela A, Rello J. (2007). Optimal management therapy for Pseudomonas aeruginosa ventilator-associated pneumonia: an observational, multicenter study comparing monotherapy with combination antibiotic therapy. Crit Care Med. 35(8):1888-95. http://dx. doi.org/10.1097/01.CCM.0000275389.31974.22

[19] Mah TF, Pitts B, Pellock B, Walker GC, Steward PS, O'Toole GA (2003) Agenetic basis for P. aeruginosa biofilm antibiotic resistance. Nature 426 (6964):306-10

[20] Bassetti M, Vena A, Croxatto A, Righi E, Guery B. (2018). How to manage Pseudomonasa eruginosa infections. Drugs in Context 2018; 7: 212527. DOI: $10.7573 /$ di dic. 212527

Citation: Muhammad Ali, Sani U. Diso, et.al. Characterization and Determination of Antibiotic Sensitivity Profile of Pseudomonasaeruginosa Isolated from Infected Wound 2019; 4(2):13-17. doi:dx.doi.org/ 10.20431/2456-0022.0402004.

Copyright: (C) 2019 Authors. This is an open-access article distributed under the terms of the Creative Commons Attribution License, which permits unrestricted use, distribution, and reproduction in any medium, provided the original author and source are credited. 